desire of the consumer is to satisfy his hunger; and even though bread prices are kept high, bread generally still remains the cheapest way of doing this. Paying more for the bread he eats is equivalent to a reduction in the real income of the consumer, with the result that his purchases of the higher-priced protective foods are restricted, with consequent deterioration of the diet.

Evidence is adduced, in the chapter on the relation of income to nutrition, that usually the sources of 'good' protein and foods rich in minerals and vitamins are more expensive than the purely energy-bearing foods. This applies particularly to fruit, vegetables, meat, fish and eggs; while dairy products-also 'highly' protective-occupy an intermediate position. These foods, though expensive as sources of calories, are relatively cheap as sources of minerals and vitamins; their expense, however, militates against their consumption by the poorer sections of any community. With rising income, calories are purchased from more varied and expensive sources, which are usually more nutritive; thus a steady increase in the percentage of both proteins and calories derived from animal sources has been found to accompany a rising income per consumption unit. The evidence for the existence of malnutrition in many countries is supplemented by studies of the cost of adequate diets, which disclose the fact that the incomes of the poorer sections of the population are aetually insufficient to provide their members with a minimum adequate diet.

Finally, the report gives consideration to methods of improving nutrition; it insists, in the first place, that the problem must be recognized as one of primary national importance. It recommends the establishment in each country of National Nutrition Committees, containing scientific investigators, economists, agricultural experts, consumers' representatives, teachers and administrators, which would initiate investigations into the facts of nutrition, educate the consumers and make recommendations for improving the national diet. The report recommends the extension of social legislation for the protection and improvement of the health of the people, and directs attention to the value of school meals and to methods for increasing the consumption of milk. Policy must also be directed towards helping the orderly expansion of agriculture and its adaptation to the changing demand; at the same time, attention must be given to improvement of transport and distribution, with the view of reducing the margin between the price received by the producer and that paid by the consumer. Adequate nutrition must be one of the factors considered by each country in determining its economic policy.

\title{
Investigation of the Upper Air
}

$\mathrm{A}^{\mathrm{T}}$ T the Nottingham meeting of the British Association a discussion on the upper air which was held on the morning of September 6 was preceded by a demonstration of the ascent of a sounding balloon, organized by Prof. D. Brunt. The demonstration attracted the attention of large numbers of members of the Association, as well as of the general public. The balloon carried a Dines meteorograph, recording pressure, temperature and humidity at all stages of the ascent. The instrument was attached to the balloon by a Baker release, which consists of a small aneroid box with a catch capable of being set so that it is released from the balloon at any desired height. In the demonstration the catch was set to liberate the instruments at a height of about 12 kilometres.

The instruments were in fact released from a height of $12 \cdot 3 \mathrm{~km}$., and were found 4 miles east of Grantham and returned to Kew Observatory in good condition. The record of the meteorograph showed that the balloon had probably entered the stratosphere at a height of $12 \mathrm{~km}$., where the temperature was $-55^{\circ} \mathrm{C}$. The temperature fell steadily through the whole range of height attained, except in a layer from $\frac{1}{2}$ to $1 \mathrm{~km}$. above the ground, where it increased by about $1^{\circ} \mathrm{C}$. The record of humidity, which was probably only reliable in the lower half of the ascent, showed no features of particular interest. The general features of the temperature record agreed with those shown by the aeroplane ascent at Mildenhall on the same morning.

In the subsequent discussion in Section $\mathrm{A}$, Prof. D. Brunt explained the division of the atmosphere into troposphere and stratosphere, and explained why frequent measurements of temperature and humidity in the free air are of importance to the forecaster. The method demonstrated before the meeting has the disadvantage that days or even weeks may elapse before the record of the Dines meteorograph, or any other instrument sent up on a free balloon, is available for study. The alternative method of upper air observation which is in general use in 
meteorological services is that of observing from an aeroplane. This method is expensive and is restricted to those days when it is possible for an aeroplane to fly. In consequence, efforts are now being made to develop wireless methods.

Mr. L. H. G. Dines, of Kew Observatory, described the meteorograph in greater detail, and showed a number of specimen records obtained by its use. On account of the lightness of the instrument, it can be sent up with any other instruments used for the investigation of conditions in the upper air.

Prof. K. O. Lange, of Blue Hill Observatory, Harvard University, described a wireless transmitter which has been developed at Blue Hill, for use on balloons in conjunction with a receiver at the ground. The transmitter sends out waves of constant frequency, and the aim of the designer of the instrument is to replace the measures of the meteorological elements by time intervals. The meteorological instruments are an aneroid, a bimetallic thermometer and a hygrometer. Each of these instruments is equipped with a pen arm, and these pen arms, together with a fixed pen, slide over a small cylinder on which is wound a fine platinum wire in the form of a helix. The helix and the pens are wired to the transmitter, and the cylinder on which the helix is wound is rotated by a clockwork which makes two revolutions per minute. The contacts of the fixed pen with the helix bring the transmitter into action at regular intervals of $\frac{1}{2}$ minute, while the pens attached to the meteorological instruments bring the transmitter into action at times which are determined by the readings of these instruments. The signals being recorded on the drum of a chronograph, the lags between the records given by the moveable pens and the fixed pen are readily estimated and converted into the readings of the corresponding meteorological element.
The instrument shown by Prof. Lange is extremely compact, being contained in a small wooden box, the external dimensions of which do not exceed 8 in. $\times 4$ in. $\times 3$ in. This method is now being adopted at some of the upper air stations in the United States, instead of the aeroplane ascents which have hitherto provided the data required for weather forecasting. It is likely that the same or similar instruments will be in general use in many parts of the world within a few years, in view of the saving of money, combined with the enormously increased frequency of observations, which will be obtained when this method supplants the aeroplane. The use of such instruments will open up the possibility of obtaining observations of the conditions in the central part of depressions and in other conditions when it is impossible for an aeroplane to make an ascent, as in rain or fog.

Prof. F. A. Paneth, in continuing the discussion, explained the methods by which he and Mr. Dines had obtained samples of air at high levels in the atmosphere, and showed some of the results of analysing these samples. The most interesting result so far obtained is the apparent increase in the proportion of helium present in air at levels of $25 \mathrm{~km}$. and upward, indicating a tendency for the component gases of the atmosphere to separate out according to their molecular weights at such levels in the atmosphere. Further observations will be required before this can be accepted as conclusively proved. Prof. Paneth emphasized the importance of analysing samples of air from high levels for their water-vapour content. In view of the fact that nearly all the radiation and absorption of long-wave radiation in the atmosphere are produced by water vapour, it is of the greatest interest to meteorologists to know how much water vapour actually is present at high levels in the atmosphere.
D. B.

\title{
The Percy Sladen Expedition to Lake Titicaca*
}

\author{
By H. C. Gilson, Leader of the Expedition
}

CINCE April 14, the day after the arrival of the $\checkmark$ main body at Puno, the Expedition has been established in a hacienda (Camjata) on the peninsula of Capachica, which bounds the north side of Puno Bay (see Fig. 1). The first fortnight was spent settling in, arranging laboratory

* See also the article by Prof. J. Stanley Gardiner in NATURE of Feb. 27, 1937, p. 353 . accommodation, and transporting all our numerous cases of apparatus and equipment out from Puno, a four-hour trip by motor launch. During this time a good deal of miscellaneous collecting was done in the ponds and streams of the peninsula, but it was not until the beginning of May that work on the lake could be started in earnest. Since then routine hydrographical and chemical observations 